AperTO - Archivio Istituzionale Open Access dell'Università di Torino

\title{
Ductility and toughness of cold-rolled metallic glasses
}

\section{This is the author's manuscript}

Original Citation:

Availability:

This version is available http://hdl.handle.net/2318/117313

since 2016-09-06T16:33:00Z

Published version:

DOI:10.1016/j.intermet.2012.09.026

Terms of use:

Open Access

Anyone can freely access the full text of works made available as "Open Access". Works made available under a Creative Commons license can be used according to the terms and conditions of said license. Use of all other works requires consent of the right holder (author or publisher) if not exempted from copyright protection by the applicable law. 


\section{UNIVERSITÀ DEGLI STUDI DI TORINO}

This Accepted Author Manuscript (AAM) is copyrighted and published by Elsevier. It is posted here by agreement between Elsevier and the University of Turin. Changes resulting from the publishing process - such as editing, corrections, structural formatting, and other quality control mechanisms - may not be reflected in this version of the text. The definitive version of the text was subsequently published in

P. Rizzi, A. Habib, A. Castellero, L. Battezzati Intermetallics 33 (2013) 38-43

http://dx.doi.org/10.1016/j.intermet.2012.09.026

You may download, copy and otherwise use the AAM for non-commercial purposes provided that your license is limited by the following restrictions:

(1) You may use this AAM for non-commercial purposes only under the terms of the CC-BY-NC-ND license.

(2) The integrity of the work and identification of the author, copyright owner, and publisher must be preserved in any copy.

(3) You must attribute this AAM in the following format: Creative Commons BY-NC-ND license (http://creativecommons.org/licenses/by-nc-nd/4.0/deed.en),

P. Rizzi, A. Habib, A. Castellero, L. Battezzati

Intermetallics 33 (2013) 38-43

http://dx.doi.org/10.1016/j.intermet.2012.09.026 


\author{
Ductility and toughness of cold-rolled metallic glasses \\ P. Rizzi ${ }^{*}$, A. Habib ${ }^{1}$, A. Castellero, L. Battezzati \\ Dipartimento di Chimica and NIS, Università di Torino, via P. Giuria 7, 10125 Torino, Italy
}

\begin{abstract}
Cold rolling of $\mathrm{Al}_{87} \mathrm{Ni}_{7} \mathrm{La}_{6}$ amorphous ribbons was performed on ribbons embedded in pure $\mathrm{Al}$ foils and ribbons alone, in order to study their deformation under constraint. A shange in behaviour was abserved for the tw seriec of samplec due to _ different distribution, so that ribbons alone was deformed up to $31 / 40.029$ without formation of cracks while, for composite samples, small fragments were always formed. In ribbons rolled alone, along with a macroscopic strain, a plastic deformation was observed at a finer scale, in the cavities present on the ribbon surface. The locally induced strain was quantified by taking into account the size change of cavities in samples rolled to different extents. The formation of shear bands and fracture occurring during cold rolling was studied for composite samples: the shear offset, interband spacing and distribution of fracture angles were determined. $\mathrm{A}_{5} \mathrm{Zr}_{5} \mathrm{Al}_{20} \mathrm{Ni}_{12} \mathrm{Cu}_{8} \mathrm{Ti}_{5}$ amorphous ribbon was rolled with $\mathrm{Al}$ foils and the toughness value was estimated from the shear band
\end{abstract}

offsets finding good agreement with literature data. Therefore, the toughness was estimated also for the Al-based samples obtaining the value of $\mathrm{K}_{\mathrm{c}} 1 / 428 \mathrm{MPa} \mathrm{m}$.

\section{Introduction}

The mechanical properties of amorphous alloys have been the subject of intensive research in recent years [1]. These materials are generally brittle and their ductilisation has proved to be difficult. At temperatures far below the glass transition, deformation is inho-mogeneous and takes place via shear softening along bands. In absence of constraints, the shear band activity proceeds unper-turbed and the sample fails along a dominant band before detect-able plastic deformation can occur. According to the state of the art [2], the most effective way of achieving large deformation of metallic glasses is processing them under constraint. In these conditions, deformation takes place via the activity of shear bands within the glass which finds an obstacle to their propagation in the constraining medium. Evidences of this are frequent: from the extensive formation of shear bands underneath an indenter tip [3] to elongation of amorphous alloys well beyond the elastic limit during rolling [4].

Because of their high strength metallic glasses have been considered as candidate reinforcements in metal matrix compos-ites. Early examples include aligned ribbons in various matrixes:
$\mathrm{Fe}_{42} \mathrm{Ni}_{42} \mathrm{~B}_{16}$ in $\mathrm{Ni}$ [5], $\mathrm{Ni}_{78} \mathrm{Si}_{10} \mathrm{~B}_{12}$ in $\mathrm{Cu}$ [6], and $\mathrm{Ni}_{19} \mathrm{Si}_{7} \mathrm{~B}_{2}$ (wt\%) in Cue30Zn brass [7.8]. Tensile tests of the composites showed that the glassy reinforcement could be deformed to a substantial extent while constrained inside the ductile matrix. The strength of the composites followed the rule of mixtures. More recently, a composite made of warm pressed $\mathrm{Al}$ and $\mathrm{Al}_{85} \mathrm{Y}$ ${ }_{8} \mathrm{Ni}_{5} \mathrm{Co}_{2}$ powders displayed improved plastic properties according to the isostress model [9].

In a previous work [10] the repeated co-rolling of stacked layers of an $\mathrm{Al}_{87} \mathrm{Ni}_{7} \mathrm{La} 6$ amorphous ribbon embedded in a pure $\mathrm{Al}$ matrix was studied with emphasis on the constrained deformation of the amorphous component at room temperature. The ductile $\mathrm{Al}$ adapted to the surface roughness of the ribbon with stress concentration at weak points, where fracture occurred. A large amount of shear bands was found both parallel and perpendicular to the deformation direction. Larger shear offsets were found near the fracture surface and were attributed to the effect of the stress concentration at weak points after the constraints hindered the slip of previously formed shear bands. SEM studies of ribbon fragments evidenced mostly the occurrence of brittle fracture surfaces with limited number of vein patterns indicating that mostly cold shear bands were operative $[11,12]$.

This paper extends the previous findings by first comparing the deformation of a ribbon alone and an $\mathrm{Al} /$ metallic glass composite in terms of rolling fundamentals, then the extent and type of defor-mation is quantified by observing the reduction in size and the final disappearance of surface imperfections in ribbons not embedded in 
a matrix. Finally, the shear band offset and length in the composites are used to estimate the toughness of the $\mathrm{Al}_{87} \mathrm{Ni}_{7} \mathrm{La}_{6}$ metallic glass by applying the model successfully developed for $\mathrm{Ni}_{1} \mathrm{Si}_{7} \mathrm{~B}_{2}$ [13]. The result for the Al-based glass is validated by performing an analogous estimate for a $\mathrm{Zr}_{55} \mathrm{Al}_{20} \mathrm{Ni}$ ${ }_{12} \mathrm{Cu}_{8} \mathrm{Ti}_{5}$ amorphous alloy of known toughness.

\section{Experimental}

$\mathrm{Al}_{87} \mathrm{Ni}_{7} \mathrm{La}_{6}$ amorphous ribbons in between 30 and $40 \mathrm{~mm}$ thick were produced by melt spinning $[14,15]$. Two series of samples were then prepared for cold rolling tests: ribbons embedded in pure $\mathrm{Al}$ foils and ribbons alone. Because of the low sample thick-ness, in both cases the cold rolling was performed by inserting samples in a stainless steel envelope, that was prehardened by rolling in order to favour the transmission of strength from rolls to samples.

Ribbons were cold-rolled alone for 6, 12 and 30 rolling passes in order to achieve different amounts of plastic deformation. The elongation was determined by measuring the ribbon length before $\left(1_{0}\right)$ and after (l) cold rolling. Plane strain conditions were assumed during rolling so that the strain (3) can be calculated as $31 / 4 \ln (1 / 10)$. Scanning Electron Microscopy (SEM) was performed on samples before and after cold rolling in order to determine changes in the surface morphology during deformation. The cavity dimensions, length and width, were determined from the SEM images measuring between 75 and 275 cavities depending on the sample.

The composite samples were prepared by placing $\mathrm{Al}_{87} \mathrm{Ni}_{7} \mathrm{La} 6$ ribbons about $2 \mathrm{~cm}$ long between two foils of pure $\mathrm{Al} 100 \mathrm{~mm}$ thick and $2 \mathrm{~cm}$ long. The amount of glassy ribbons was chosen so that their volume fraction with respect to $\mathrm{Al}$ was $20 \%$. This ratio was chosen by considering the hypothetical strength of an Al-based composite containing aligned fibres. At this ratio, the effect of fibres should start prevailing over that of the matrix. During processing, the fibres did not remain homogeneously distributed, however, no relevant difference in deformation and fracture mode could be detected.
Samples were rolled in the stainless steel envelope. Folding the Al-ribbon composite was necessary when its length became comparable to that of the steel container and when the thickness of the rolled composite became too thin. With this setting it was found that all ribbon samples fractured inside the Al foils irre-spective of the number of foldings and passes [10]. These samples were studied in cross section by SEM in order to reveal the presence of shear bands and to highlight their fracture behaviour.

$\mathrm{Zr}_{55} \mathrm{Al}_{20} \mathrm{Ni}_{12} \mathrm{Cu}_{8} \mathrm{Ti}_{5}$ amorphous ribbons produced by melt spin-ning were also cold-rolled inside $\mathrm{Al}$ foils, with the same experi-mental conditions used for the Al-based samples. Also in this case, samples fractured inside the $\mathrm{Al}$ foils and were analysed as detailed above.

\section{Results}

\subsection{Ductility during cold rolling}

All glassy samples display manifest permanent deformation which can be quantified for the ribbons rolled alone. The elongation (3) is $0.011,0.013$, and 0.029 after 6,12 , and 30 rolling passes, respectively. There was no evident formation of cracks during rolling up to 30 rolling passes. Further rolling causes crack initiation.

As well known, ribbons produced by melt spinning have a typical roughness on the surface, i.e. the side solidified in contact with the copper wheel (wheel side) presents lines due to the wheel roughness and cavities due to gas bubbles that remains entrapped between the melt and the quenching wheel. In Fig. 1a, an example of the wheel side of the as quenched $\mathrm{Al}_{87} \mathrm{Ni}_{7} \mathrm{La}_{6}$ ribbon is reported, in which cavities appear homogeneously distributed on the ribbon surface.

During rolling, besides the already mentioned macroscopic plastic deformation measured by the increase in sample length, plastic deformation is seen also at a finer scale in ribbon cavities. In Fig. 1b, a SEM image of the sample rolled 30 times is reported showing evident reduction of the cavity dimensions with respect to

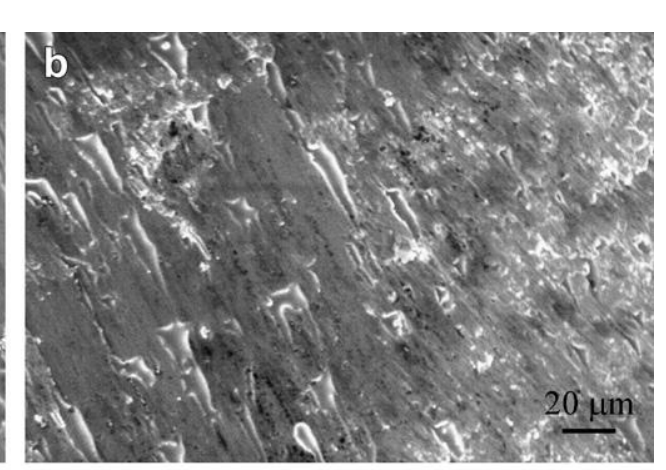

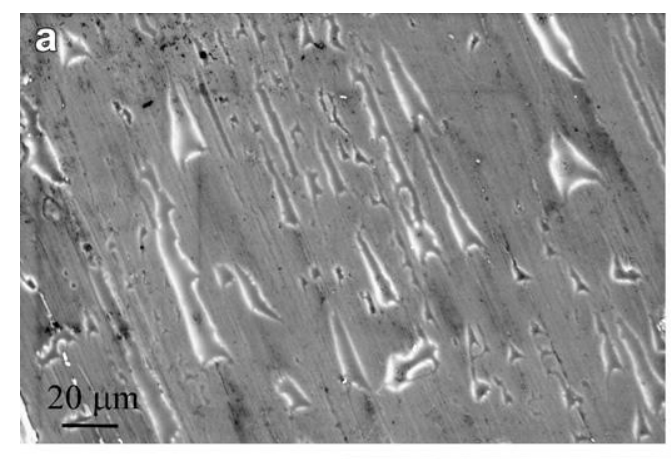

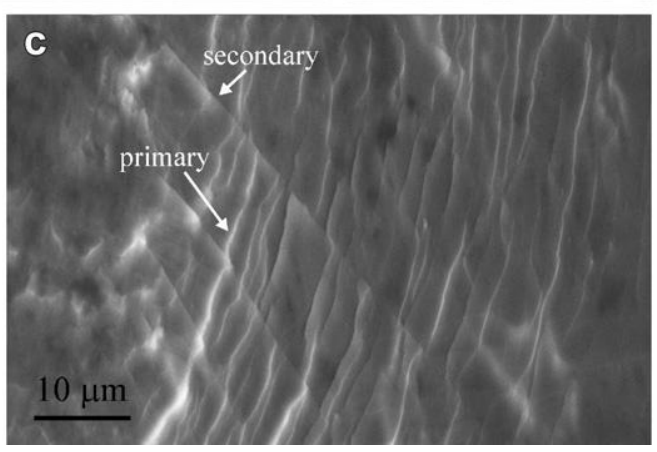

Fig. 1. Secondary electrons SEM image of the wheel side surface of the as quenched ribbon (a) and after 30 rolling passes (b), showing the decrease of the cavities size with strain. Deformation occurs through activation of primary and secondary shear bands (c). 
the sample before cold rolling (Fig. 1a). The flow of matter during rolling is due to the formation of a large number of shear bands which causes the observed increase in length, reduction in thick-ness and change of the surface morphology in the samples as well as filling of the cavities. Due to the irregular surface morphology of the ribbons, an uneven stress distribution can be expected, with consequent formation of shear bands in different directions. An example of multiple shear bands formation is reported in Fig. 1c, where a magnified image of a surface area of the sample rolled 30 times is reported, in which discontinuous primary and continuous secondary shear bands are identified in two intersecting directions. In the left part of Fig. 1b, an almost flat surface appears. This was probably a thicker part of the ribbon, where cavities almost dis-appeared due to flow of matter during rolling. The absence of shear bands can be due to successive rolling passes that tend to flatten the shear offsets formed during previous deformation steps.

From Fig. 1 it is apparent that a large amount of plastic defor-mation occurs during rolling because of the irregularity of the surface of the ribbon that is not evidenced by the mere determi-nation of the ribbon length or thickness. It is therefore envisaged that the material can undergo more deformation than suggested by its macroscopic behaviour. To put this in evidence, a statistical analysis of the cavities dimensions was done. The length and width of a large number of cavities at each deformation stage were measured and results are reported in Figs. 2 and 3, respectively. In the asquenched sample the distributions are broad, ranging from $7 \mathrm{~mm}$ to $89 \mathrm{~mm}$ for the length (Fig. 2a) and from $3 \mathrm{~mm}$ to $21 \mathrm{~mm}$ for the width (Fig. 3a). In the course of rolling (Fig. 2bed and Fig. 3be d for length and width, respectively), distributions become nar-rower. The SEM image in Fig. 1b shows that some of the cavities are completely filled during rolling and disappear leaving a nearly flat surface in their place. Larger cavities are only partially filled becoming smaller. The average values of length and width for all

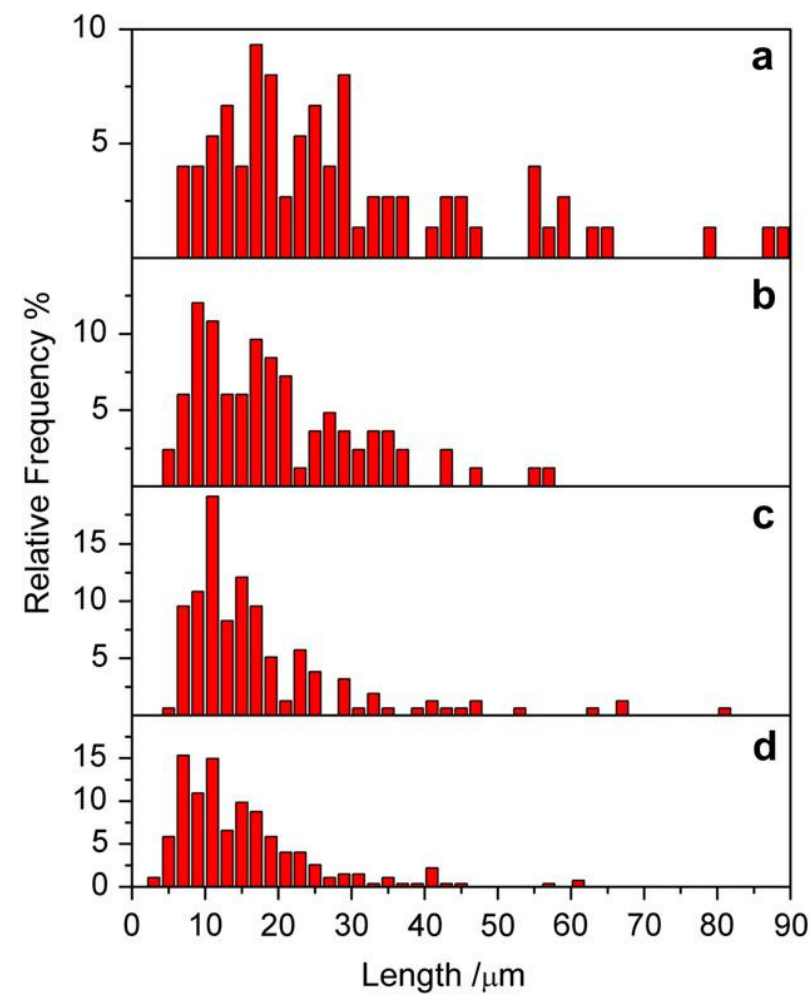

Fig. 2. Distribution of the cavities length for the as quenched ribbon (a), after 6 (b) 12 (c) and 30 (d) rolling passes.

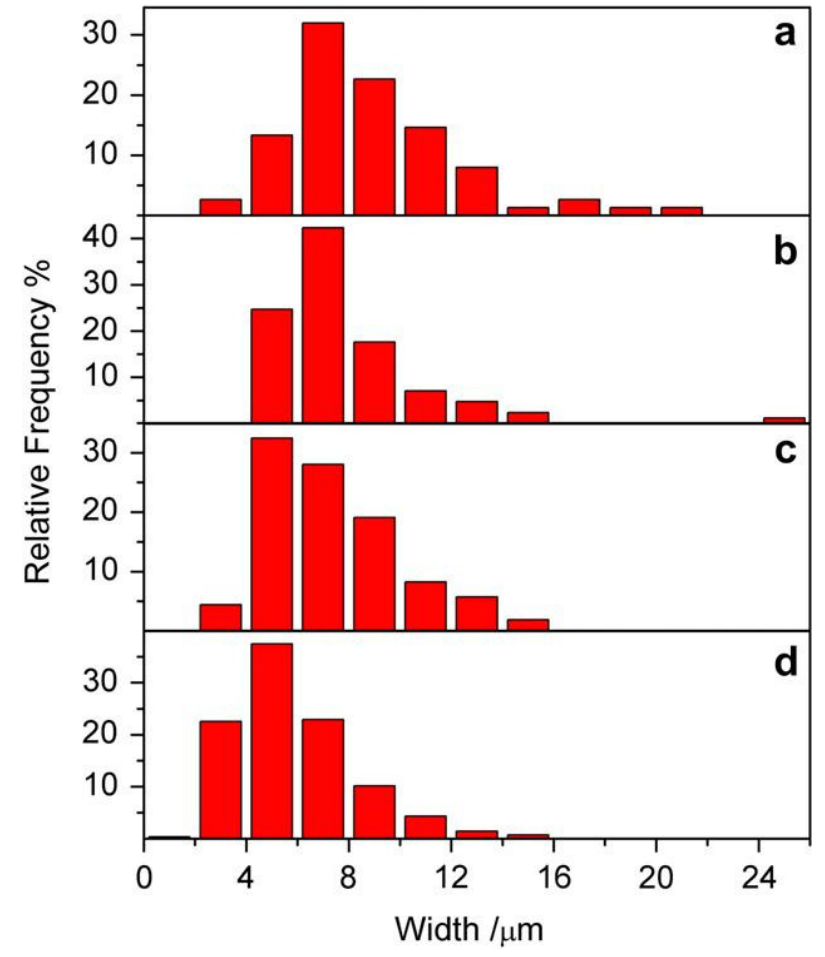

Fig. 3. Distribution of the cavities width for the as quenched ribbon (a), after 6 (b), 12 (c) and 30 (d) rolling passes.

samples, calculated together with the corresponding standard deviation from the respective distributions, are reported in Fig. 4a and b, respectively, showing a progressive decrease in size of the cavities with increased rolling.

\subsection{Shear banding and fracture}

In composite samples the deformation is related to the local stress distribution. In particular, during rolling, pure Al fills cavities present on the surface of the ribbon and uniformly transmits the force from the rolls to the ribbon. Assuming the force causes the same shear displacement both in the thin and thick parts of the ribbon, the thinner part will experience higher stress. As a conse-quence, fracture occurs frequently in the thin sections during rolling. In Fig. 5, a typical SEM image of a cross section of rolled composite sample is reported where ribbons fragments appear, brighter with respect to pure $\mathrm{Al}$, displaying several shear bands offsets. The width of fragments ranges from $8 \mathrm{~mm}$ to $16 \mathrm{~mm}$ and length from $30 \mathrm{~mm}$ to $140 \mathrm{~mm}$ in all samples.

The shear strain in the samples rolled in $\mathrm{Al}$ foils was quantified by determining the ratio between the shear band offset and the spacing between two neighbouring shear bands (Fig. 6). A larger amount of deformation is experienced by shear bands that are close to the fracture surface. The shear deformation near the fracture surface can reach values around unity while an average shear deformation of about 0.3 occurs far from the fracture surface.

The distribution of the fracture angles in the ribbon fragments (Fig. 7) is skewed with a clear maximum around $45^{-}$and evidence of increased frequency between $30^{-}$and $34^{-}$. The presence of such a distribution can be explained with the help of Fig. 5. When the rolling direction is the same in subsequent passes, the deformation can be accommodated by creation of new shear bands or reac-tivation of pre-existing shear bands along a direction parallel to the previous shearing direction (indicated by arrow 1 in Fig. 5) with an 

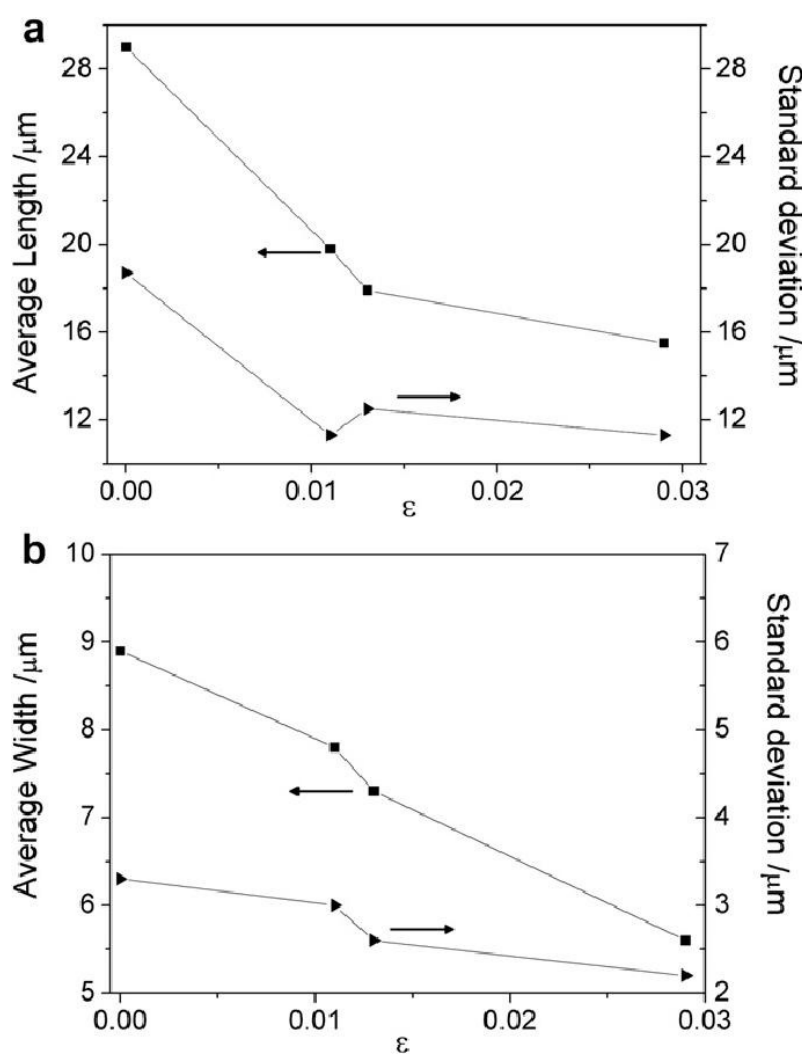

Fig. 4. Average length of the cavities with the corresponding standard deviation as a function of strain (a). Average width of the cavities with the corresponding standard deviation as a function of strain (b).

angle around $45^{-}$. When the sandwiched ribbon is folded, the broken fragments of the ribbon likely adopt new orientations. Therefore, as a consequence of the rolling passes following the folding, new shear bands become operative along a new direction (indicated by arrow 2 in Fig. 5) crossing the pre-existing shear bands. In the case illustrated in Fig. 5, the new band shears along direction 2 through a thin ligament between two portions of material that were previously sheared along direction 1 , leading to

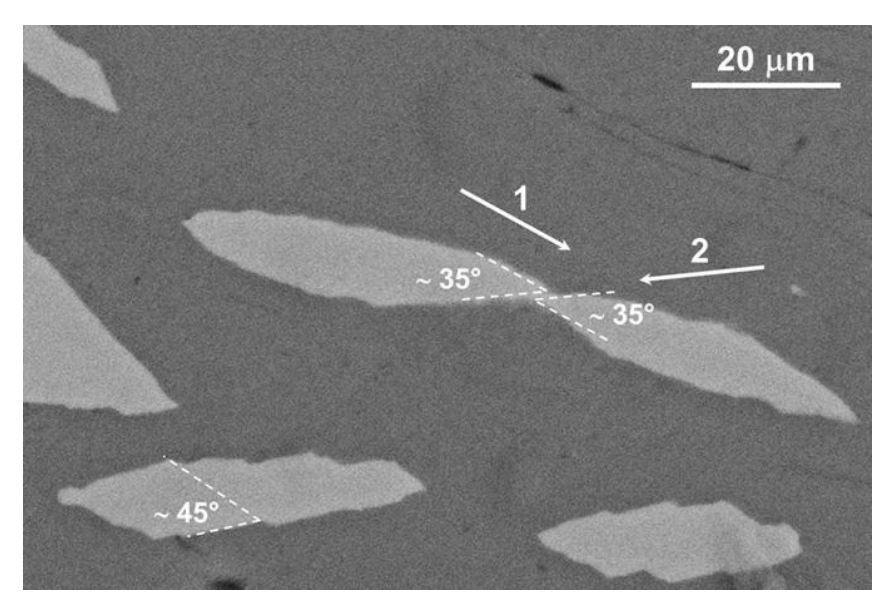

Fig. 5. Backscattered electrons SEM image of a fragment of an Al-based ribbon on the edge of breaking inside the $\mathrm{Al}$ constraining matrix. The fracture angle around $35^{-}$ results from the intersection of shearing directions before and after sample folding, respectively indicated by arrow 1 and arrow 2 . The angle around $45^{-}$is related to the shear of a band activated before folding the sample.

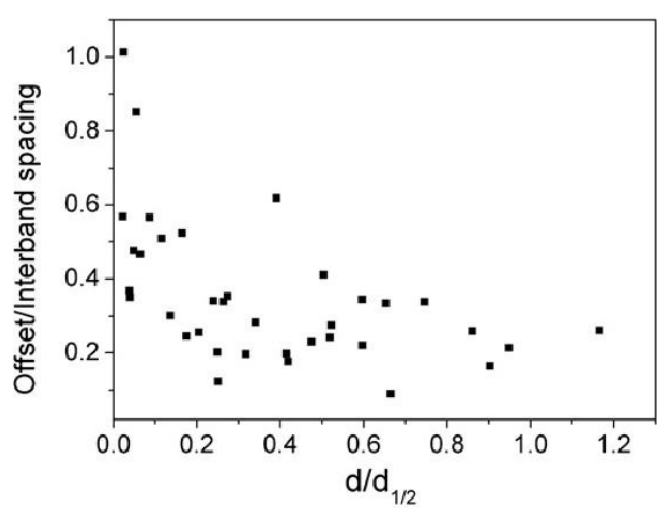

Fig. 6. Ratio between the shear band offset and the interband spacing as a function of strain.

fracture with an angle around $35^{-}$. Therefore, the increased frequencies of fracture angles mentioned above, derive from mere geometrical reasons.

The occurrence of the shear at angles around $45^{-}$is in agree-ment with previous findings obtained for some bulk metallic glasses [16e18], where similar values for the angle between shear bands and rolling direction were reported when the thickness reduction did not exceed $10 \%$.

\section{Discussion}

\subsection{Stress effect during cold rolling}

Ribbons rolled alone were contained in between hardened steel foils. The load generally vary at different points according to the ribbon-steel contact also considering the occurrence of local imperfections produced by the melt quenching process that cause a variation in thickness of the ribbon. In this condition of load transmission the sample is not subject to failure.

The maximum pressure exerted by the rolls exceeds the tensile strength of the steel foils which are elongated during the process. The rolling pressure, $p$, at the points of extensive contact with the ribbon is given by [19]

$$
\mathrm{P}
$$

p $1 / 4 \mathrm{bL}$

where $\mathrm{P}$ is the applied load, $\mathrm{b}$ is the width of the foil and $\mathrm{L}$ is the roll-foil contact length. The maximum load experienced by both foil and

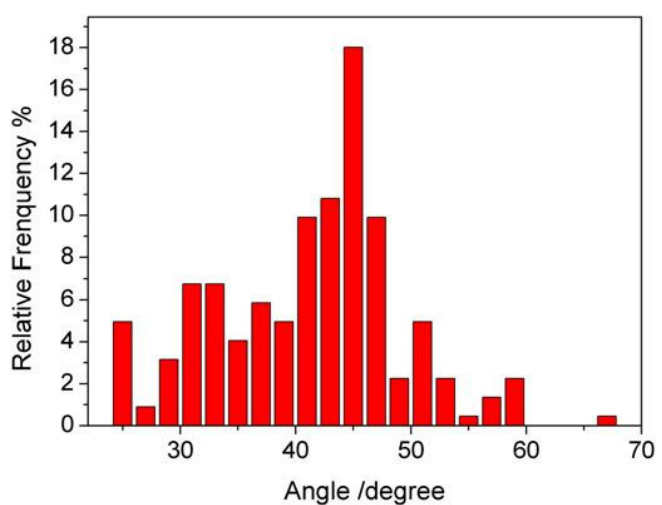

Fig. 7. Distribution of the fracture angle for the ribbons rolled in the $\mathrm{Al}$ constraining matrix 
ribbon is the same, as well as the contact length since the ribbons were aligned to the rolling direction. The ribbon then experiences a higher pressure with respect to the foil due to its smaller width (of the order of 50 times). We note also that if there were no friction between ribbon and foil, the ensemble would behave as a single body. However, because of the inevitable friction during load transfer [19], the actual rolling load on the ribbon is reduced with respect to the total load. The enhanced load on the ribbon assures the pressure is in excess of the yield stress of the metallic glasses studied here. There has been, however, local loss of contact and of load transfer in correspondence of surface imperfections.

In composite samples where the ribbon is contained within Al foils, the load is always fully transmitted to the metallic glass through the soft $\mathrm{Al}$ matrix which practically operates as a hydraulic transmitting medium. In the first rolling pass the $\mathrm{Al}$ adapts to the ribbon surface penetrating the undulations and cavities and providing mechanical grip. This minimizes the friction force along the ribbon which is then strongly compressed and sheared, with consequent fracture. A similar load transmission during compres-sion testing of a bulk metallic glass was observed when a soft metal was employed as a solid lubricant between sample and platens to reduce the contact friction. In this case, an enhanced plastic deformation was observed [20].

\subsection{Ductility under constraint}

When ribbons are rolled alone, the average length (Fig. 4a) and average width (Fig. 4b) shift to low values while the deformation proceeds. This can be regarded as an indication of the plastic deformation occurring during cold rolling in ribbons at a fine scale, while the 3 values reported before can be used as an indicator of the macroscopic plastic deformation produced during cold rolling. In particular, the deformation can be calculated as $\ln \left(\mathrm{s}_{\mathrm{s}} / \mathrm{s}_{0}\right)$, where $\mathrm{s}_{0}$ and $\mathrm{s}$ are the average dimensions of cavities before and after deformation, respectively. The reduction in length of cavities occurring along the rolling direction is more pronounced with respect to that in width showing the nonuniformity of stress distribution. The values obtained in this way indicate that plastic deformations in excess of 0.5 can be achieved after 30 rolling passes without observing crack formation.

\subsection{Shear band evolution and fracture}

The trend shown in Fig. 5 derives from the different behaviour of the shear band offset and interband spacing as a function of the distance along the ribbon fragments embedded in the $\mathrm{Al}$ foil. In fact, the shear band offset tends to become larger towards the fracture surfaces while the interband spacing remains approximately constant along the whole ribbon length [10].

When rolling Zr-based bulk metallic glasses alone, Liu et al. [18] observed a saturation of the primary shear band density after about 5e7\% strain, while the shear band offset progressively increased with rolling, suggesting that, after a relatively small strain, the deformation occurs through the reactivation of pre-existing shear bands without formation of new ones.

A similar interpretation can be inferred for the results of this work, even if the interband spacing and shear offset were not recorded as a function of strain. In fact, the value of shear offset ( $\mathrm{w} 8 \mathrm{~mm}$ ) near the surface fracture is comparable with the one re-ported by Liu et al. [18] after 7\% thickness reduction, when primary shear bands were already saturated. Similar values of the shear offset are found also for a $\mathrm{Zr}_{55} \mathrm{Al}_{20} \mathrm{Ni}_{12} \mathrm{Cu}_{8} \mathrm{Ti}_{5}$ amorphous ribbon after rolling in between $\mathrm{Al}$ foils (Fig. 8). The uniformity of shear bands density along the length, which results to be independent of the shear offset, suggests that saturation of shear bands is reached

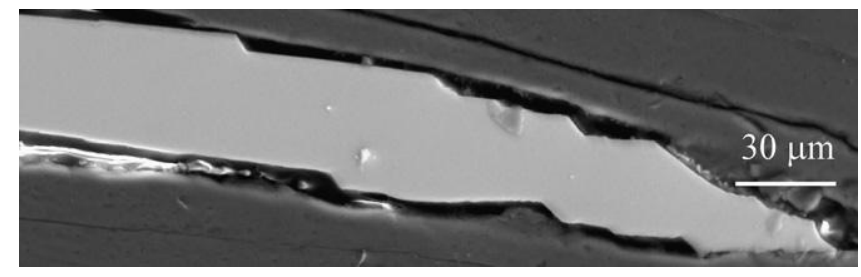

Fig. 8. Backscattered electrons SEM image of a fragment of a Zr-based ribbon showing shear offsets and fracture after rolling inside the $\mathrm{Al}$ constraining matrix.

after the repeated rolling and folding of the sample. As a conse-quence, it can be assumed that deformation proceeds through the reactivation of pre-existing bands when the rolling direction remains the same during subsequent passes: the shear offset becomes more pronounced in proximity of the cavities because of stress concentration and fracture occurs at an angle around $45^{-}$ when a critical shear band becomes dominant.

\subsection{Toughness}

In a study of the fracture behaviour in tension of laminated metal-metallic glass composites ( $\mathrm{Ni}_{91} \mathrm{Si}_{7} \mathrm{~B}_{2}$ in a $\mathrm{Cue} 30 \mathrm{Zn}$ brass matrix) multiple shear bands were found on the fracture surface of the glassy reinforcement displaying offset of similar extension as those found in the present work. Experiments of resistance to crack growth provided a value for the critical stress intensity factor, $K_{c}$, from which the energy release rate, $G_{c}$, was computed as [13]

$$
\mathrm{K}^{2}
$$

$\mathrm{G}_{\mathrm{c}} 1 / 4 \mathrm{E}$

where $\mathrm{E}$ is the Young's modulus and $\mathrm{M}$ a factor of order unity for plane stress conditions met by the shear fracture of the glass. $G$ was then expressed as the fracture work, W, per unit thickness of the ribbon, t, i.e.

$$
G_{c} 1 / 4 \frac{W}{t} \quad \frac{S_{y} T}{2 t} \quad 1 / 4 S_{y} \frac{t}{2 \cos q}
$$

where $S_{y}$ is the shear fracture stress, $T$ is the length of the shear band forming an angle $\mathrm{q}$ to the normal to the ribbon. Using measured values of $\mathrm{T}$ and $\mathrm{q}$, the model proved consistent with experiments since the computed $2 \mathrm{~S}_{\mathrm{y}}$ corresponded to the yield stress of the glass within a reasonable scatter.

Taking advantage of this demonstration, we use the model in the inverse sense to estimate the critical stress intensity factor of the Al-based glass. From collections of data on mechanical prop-erties of metallic glasses [21,22], the tensile fracture stress of the Al-glass is taken as $1155 \mathrm{MPa}$ and the shear stress as $577 \mathrm{MPa}$. The

ribbon thickness is $20 \mathrm{~mm}$ and the fracture angle $45^{-}$(Fig. 5). Finally we get $\mathrm{K}_{\mathrm{c}} 1 / 428 \mathrm{MPa} \mathrm{m}^{1 / 2}$.

To confirm further this finding, a $\mathrm{Zr}_{55} \mathrm{Al}_{20} \mathrm{Ni}_{12} \mathrm{Cu}_{8} \mathrm{Ti}_{5}$ ribbon was rolled together with $\mathrm{Al}$ foils with the same procedure used for the

Al-glass (Fig. 8). Here the relevant quantities are: $\mathrm{S}_{\mathrm{y}} 1 / 41700 \mathrm{MPa}$ [23], $\mathrm{t} 1 / 4$ $40 \mathrm{~mm}, \mathrm{q}^{1 / 4} 45^{-}$, E $1 / 482 \mathrm{GPa}$ [24] giving $\mathrm{K}_{\mathrm{c}}{ }^{1 / 4} 75 \mathrm{MPa} \mathrm{m}^{1 / 2}$ in

excellent agreement with the literature value of $80 \mathrm{MPa} \mathrm{m}{ }^{1 / 2}$ for an alloy of close composition [24]

\section{Conclusions}

This work shows that a significant amount of localized permanent deformation occurs in cold-rolled Al-based amorphous ribbons. A quantitative estimate of the locally induced strain could be deter-mined by measuring the size reduction of the surface imperfection (cavities)on thewheel sideof the ribbon asa function of rolling passes. 
When the amorphous ribbons are rolled in between a con-straining $\mathrm{Al}$ matrix that fully transmits the load, a consistent shear strain is achieved and fracture occurs in correspondence of the cavities acting as weak points. The progressive increase of the shear offset in proximity of the surface fracture and the uniform inter-band spacing suggest that saturation of the shear band density was reached. Thus, subsequent rolling passes in the same direction tend to reactivate pre-existing bands and shear is more pronounced in proximity of the cavities because of stress concentration.

Toughness values for Al- and Zr-based metallic glasses could be estimated from the length and offset of shear bands produced after rolling inside the $\mathrm{Al}$ matrix. The results obtained are validated by the excellent agreement with the literature value reported for a similar $\mathrm{Zr}$-based glass.

\section{Acknowledgements}

Work performed for PRIN 2008. Fondazione S. Paolo is acknowledged for support to CdE NIS.

\section{References}

[1] Schuh CA, Hufnagel TC, Ramamurty U. Acta Mater 2007;55:4067.

[2] Lewandowski JJ, Lowhaphandu P. Phil Mag A 2002;82:3427.
[3] Ramamurty U, Jana S, Kawamura Y, Chattopadhyay K. Acta Mater 2005; 53:705.

[4] Masumoto T, Maddin R. Mater Sci Eng 1975;19:1.

[5] Blank-Bewersdorff M, Köster U, Steinbrink G. J Mater Sci Lett 1989;8:796.

[6] Alpas AT, Embury JD. Scripta Mater 1988;22:265.

[7] Leng Y, Courtney TH. J Mater Sci 1989;24:2006.

[8] Leng Y, Courtney TH. J Mater Sci 1991;26:588e92.

[9] Scudino S, Surreddi KB, Sager S, Sakaliyska M, Kim JS, Löser W, et al. J Mater Sci 2008;43:4518.

[10] Rizzi P, Habib A, Castellero A, Battezzati L. J Alloys Compd 2011;509S:S275.

[11] Zhang ZF, Eckert J, Schultz L. Acta Mater 2003;51:1167.

[12] Zhang Y, Stelmashenko LA, Barber ZH, Wang WH, Lewandowski JJ, Greer AL. J Mater Res 2007;22:419.

[13] Leng Y, Courtney TH. Metall Trans A 1990;21:2159.

[14] Rizzi P, Battezzati L. J Non-Cryst Solids 2004;344:94.

[15] Battezzati L, Rizzi P, Rontó V. Mater Sci Eng A 2004;375e377:927.

[16] Yokoyama Y, Yamano K, Fukaura K, Sunada H, Inoue A. Mater Trans 2001; 42:623.

[17] Kobata J, Kimura T, Takigawa Y, Uesugi T, Kimura H, Higashi K. Mater Trans 2009;50:2355.

[18] Liu JW, Cao QP, Chen LY, Wang XD, Jiang JZ. Acta Mater 2010;58:4827.

[19] Dieter GE. Mechanical metallurgy. 2nd ed. New York: McGraw-Hill Inc.; 1976. p. 608.

[20] Scudino S, Surreddi KB, Wang G, Eckert J. Scripta Mater 2010;62:750

[21] Battezzati L, Mortarino GM. J Alloys Compd 2009;483.

[22] Battezzati L, Baldissin D, Habib A, Rizzi P. J Phys Conf Ser 2009;144: 012088.

[23] Peter WH, Liaw PK, Buchanan RA, Liu CT, Brooks CR, Horton JA, et al. Inter-metallics 2002; 10:1125.

[24] Lewandowski JJ, Wang WH, Greer AL. Phil Mag Lett 2005;85:77. 